\title{
From Waste to Profit : Assessment of a-Amylase Inhibitory and Antioxidant Activities Along with the development of an Active Packaging Film for Valorization of Pea peels \\ Taher, M. A.
}

Department of Agricultural Chemistry, Faculty of Agriculture, Mansoura University,

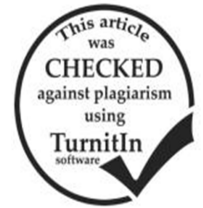
Mansoura, 33516, Egypt.

E-mail : mohamedtaher@mans.edu.eg

\begin{abstract}
The present study aimed to valorize pea peels (Pisum sativum) using new unusual aspects. In other words, to identify and quantify the phenolic profile of pea peels $80 \%$ ethanol extract (PEE), to estimate the antioxidant and anti- $\alpha$-amylase activities of successive extraction solvent fractions of the previously mentioned extract, to evaluate chitosan(Cs) / polyvinyl alcohol (PVA) / PEE edible film as antioxidant agent. The results exposed that ethyl acetate fraction had the highest amounts of polyphenols and flavonoids where their values were $165.43 \mathrm{mg} \mathrm{GAE} / \mathrm{g}$ and $26.63 \mathrm{mg} \mathrm{QE} / \mathrm{g}$, respectively. Hesperidin was documented as the most abundant polyphenol in pea peels ethanolic extract with remarkably high amount $(2017.2 \mu \mathrm{g} / \mathrm{g})$. Butanol fraction recorded considerable anti- $\alpha$ amylase activity $\left(\mathrm{IC}_{50}=1.61 \mathrm{mg} / \mathrm{ml}\right)$. The present study extremely evidenced the antioxidant activity of pea peel extracts. Besides, ethyl acetate fraction had the lowest $\mathrm{IC}_{50}$ values for $\mathrm{DPPH}, \mathrm{NO}$ and $\mathrm{H}_{2} \mathrm{O}_{2}$ assays with the values of $167.23,302.36$ and $317.66 \mu \mathrm{g} / \mathrm{ml}$, respectively. Interestingly, a significant and negative correlation was remarked between total flavonoids content and $\mathrm{IC}_{50}$ for the scavenging DPPH radical. Finally, it could be suggested that Cs/PVA film containing PEE can be used for development of active food packaging materials.
\end{abstract}

Keywords: Pea peels, phenolic compounds, antioxidant, anti- $\alpha$-amylase, edible films.

\section{INTRODUCTION}

The valorization of agricultural wastes provides our life with new products that were earlier not possible due to restrictions such as cost or the availability of natural products. Today, handling stages are already well known for the transformation of the biomass into valuable products i.e. animal feedstuff, biofuel, energy, biomaterials, heat, chemicals and food ingredients (Pathak et al., 2017). The peels of vegetables and fruits which generated during food processing are the dominant source for these purposes.

Pea waste is one of the largely available agricultural by-products throughout the world. The removal of pea peels large quantities usually represents a problem that is further aggravated by legal restrictions. In Egypt, more than 40,000 tons/year of pea are handled into frozen pea, yielding large quantities of by-product representing about $60 \%$ of the handled material, mostly composed of pericarps (Seida et al., 2015). As the waste contains a considerable proportion of hollocellulose, it can be used as a suitable choice in feedstuff. Economically and friendly to environment uses of pea wastes including the production of bioethanol, biochar and biomethane have been previously stated ( Rehman et al., 2015; Mary et al., 2016 ; Abas and Halim 2017) . Additionally, the suitability of pea peels as the solid substrate for the microbial production of industrial enzymes i.e. cellulase and xylanase has been reported (Verma et al., 2011 and Nitin et al., 2017) . In textile industry, pea peels can be used to get rid of dyes color from effluents (Basu 2016).

The uptake of methylene blue dye by pea peels was faster than that of commercial activated carbon due to the higher pore diameters of pea peels than those of commercial activated carbon (Dod et al., 2012).

Pea peels have attracted more attention due to their nutritive and therapeutic properties. In this regard, pea waste is a well-known good source of pectin ( Mualikrishna and Tharanathan 1994), and dietary fibers with bifidogenic properties (Iwata et al.,
2009).Carbohydrate percentage in excess of 61.0 has been reported (Garg 2015) . Chromatographic analysis of acid hydrolysate of pectic components showed a high uronic acids content besides arabinose, xylose and rhamnose

(Mualikrishna and Tharanathan 1994).The proximate analysis of pea waste showed that glucose was existed in higher amount (323 mg/ g d.w) than xylose $(188 \mathrm{mg} / \mathrm{g} \mathrm{d.w}$ ) (Mary et al., 2016).Pea peels from India were defined to have high contents of protein and minerals especially iron (Garg 2015). Moreover, anti-hepatotoxicity, antioxidant, antimicrobial, hypoglycemic , antihypercholesterolemic and anticancer activities of pea peels have been stated (Khattab and Abdel Wahab 2005; Seida et al. 2015; Hadrich et al. 2014; Gupta and Premavalli 2011 and El-Feky et al ., 2018 ).

Interestingly, pea peels are abundant source of quercetin-derived glycosides and these can be employed as bioactive additives for nutraceuticals usage (Seida et al., 2015). However, no available data in the literature have focused on the successive fractionation of mother ethanolic extract of pea by-product using organic solvents increasing in polarity. So, one of the objectives of the present study was to evaluate the antioxidant activity of pea peels successive fractions and to quantify their total polyphenol and flavonoid contents.

One of the therapeutic styles for alleviating type 2 diabetes mellitus (T2DM) is to suppress intestinal glucose absorption through the quench of carbohydrate hydrolyzing enzymes such as $\alpha$-glucosidase and $\alpha$-amylase (Saltos et al., 2015) . Natural $\alpha$-amylase inhibitors represent an interesting route to the management of postprandial hyperglycemia by declining glucose release from starch (Kwon et al .,2007). Therefore, one of the aims of this study is to evaluate anti $\alpha$-amylase activity of ethanolic extract, methylene chloride, ethyl acetate, butanol and water residue fractions of pea by-product using nonpre- and pre-incubation methods.

Now, the fabrication and characterization of degradable edible films have increased significantly, mostly due to interest in decreasing the ecological impact 
caused by the use of artificial packaging resources ( Lo'ay and Taher 2018). Moreover, edible films incorporated with plant extracts have established much attention in the last decade due to the existence of considerable amounts of bioactive secondary metabolites with biological properties i.e. antioxidant and anti-microbial activities (Kanatt et al., 2007 and Kanatt et al ., 2010). Edible film enriched with antioxidants improves nutritional properties without affecting the reliability of the food product (Guilbert et al., 1996).

Interestingly, blending of polymers is one of the most applicable ways to obtain a new material with preferred mechanical and physical properties compared to films made of individual components ( Lo'ay and Taher 2018). The acceptable physical and mechanical properties of chitosan- polyvinyl alcohol (Cs/PVA) biopolymer incorporated with different extracts have been reported (Kanatt et al 2012).

No available data in the literature about the usage of pea wastes crude extract in enrichment of any edible biopolymer film. Since food coated with biodegradable polymers enriched with natural antioxidant may be kept at different temperatures. Therefore, one of the aims of this study is to evaluate the release of phenolics from Cs/PVA film containing peels ethanolic extract (PEE) and its DPPH radical scavenging action at different temperatures.

Collectively, no comprehensive data in the literature concerning the valorization of pea peels for various applications, comprising their use in medicines and food preserving. So, the present study aimed to (i) identify and quantify the phenolic profile of pea waste ethanolic extract (ii) investigate antioxidant and anti-amylase activities of PEE and its fractions (iii) evaluate PVA/Cs film enriched with pea peels extract under different conditions.

\section{MATERIALS AND METHODS}

\section{Pea peels samples}

Green pea by-product (GPP) was obtained from local market. Peels were washed with distilled water, air dried for $72 \mathrm{~h}$ and powdered to a uniform size.

\section{Chemical composition of pea peels powder}

Moisture, fibers, ash, fat and protein contents were estimated using the methods described in AOAC (2000). Carbohydrates were calculated by difference.

\section{Extraction of pea peels}

The extraction process was done by soaking the powdered form of pea peels in $80 \%$ ethanol for $16 \mathrm{~h}$. After filteration, extraction route was repeated twice, then the combined extracts were evaporated under low pressure till dryness. The dried pea peels extract was packed in a beaker and stored at $-20^{\circ} \mathrm{C}$ until further use.

\section{Successive extraction of pea peels extract}

Pea peels ethanolic extract $(50 \mathrm{~g})$ was resolved in 2 liter of ethanol: water mixture $(1: 4 \mathrm{v} / \mathrm{v})$. The resultant solution was moved into a separating funnel and extracted by methylene chloride. After equilibrium the solvent layer was separated, the extraction was repeated 4 times. The residual alcoholic solution was then re-extracted using ethyl acetate and butanol, respectively. Then the solvent of each fraction was combined and evaporated using rotatory evaporator and stored under cooling till use. The residual aqueous ethanolic extract was also dried and used as individual fraction.

\section{Total polyphenol and flavonoid contents}

Total polyphenolic and flavonoid contents of pea peels ethanolic extract and its fractions were estimated according to methods described in detail by ( Singleton et al., 1999 ; Lin and Tang 2007). Different concentrations of gallic acid $(10-150 \mu \mathrm{g} / \mathrm{ml})$ were used to prepare the standard curve of total polyphenols

\section{$\left(Y=0.0074 X+0.1677, R^{2}=0.997\right)$.}

Quercetin was chosen as a standard for flavonoids in concentrations ranged between $10-100 \mu \mathrm{g} / \mathrm{ml}$

$\left(\mathrm{Y}=\mathbf{0 . 0 0 8 X}+\mathbf{0 . 0 3 2 2}, \mathrm{R}^{2}=\mathbf{0 . 9 9 7}\right)$.

\section{Identification and quantification of flavonoids}

Flavonoid constituents were identified and quantified in pea by-product ethanolic extract by an Agilent 1100 Series HPLC instrument, equipped with a diode array detector. The conditions of the assay were designated in detail by (Mattila et al., 2000).

Identification and quantification of polyphenols

Phenolics of pea by-product ethanolic extract were dissolved, then introduced into reversed phase HPLC/diode array detection (Hewlett Packard 1050) with a guard column AlltimaC18, $5 \mathrm{~mm}$. Identification and quantification of pea by-product ethanolic extract phenolic compounds was functioned according to the procedure described in details by (Goupy et al., 1999).

\section{$\alpha$-amylase inhibitory assay.}

The $\alpha$-amylase inhibition assay was done using the procedure described in details by Ali et al (2006) using $\mathrm{PEE}$ and its fractions in a final concentration of $3 \mathrm{mg} / \mathrm{ml}$, porcine pancreatic $\alpha$-amylase (EC 3.2.1.1, Sigma), corn starch, acarbose (reference anti $\alpha$-amylase inhibitor), maltose and 3,5-dinitrosalicylic acid. In the non-pre incubated experiment the reaction was initiated without any incubation period as the enzyme was directly added to a mixture containing starch and PPE or its fractions. In preincubated procedure the enzyme was pre-incubated with PPE or its fractions and the reaction was then initiated by the addition of starch solution. The released maltose amounts were valued using maltose standard curve in concentrations ranged between $50-1500 \mu \mathrm{g} / \mathrm{ml}$

$$
\text { ( } \left.Y=0.0008 X-0.0084, R^{2}=0.996\right) \text {. }
$$
calculated.

Percentages of the enzyme inhibition were then

\section{Antioxidant activity of pea peels preparations}

The scavenging activity of PPE and its fractions $(50-1000 \mu \mathrm{g} / \mathrm{mL})$ on 1,1-diphenyl-2-picrylhydrazyl radical (DPPH) , nitric oxide and hydrogen peroxide were assessed according the scheme described in details, respectively by (Shirwakar et al., 2006 ; Green et al., 1982 ; Oktay et al., 2003) . butylated hydroxyl toluene (BHT) was selected as a standard antioxidant. The percentages scavenging activities of different extracts preparations and the reference BHT were evaluated. $\mathrm{IC}_{50}$ values were then calculated

\section{Film preparation}

Biodegradable films were prepared by the casting method. One gram chitosan (Cs, MW 71.3, the degree of deacetylation $=94 \%$; Merck, Darmstadt Germany) was dissolved in $100 \mathrm{ml} 1 \% \mathrm{CH}_{3} \mathrm{COOH}$ solution with 
continuous stirring (400 rpm). Then, five grams of PVA was dissolved in hot distilled water at $70{ }^{\circ} \mathrm{C}$. PVA solution was carefully added to Cs solution $(1: 1)$, followed by adding glycerol $(0.1 \% \mathrm{v} / \mathrm{v})$ to the resultant mixture as a plasticizer. The control set was not enhanced with any improver. One $\mathrm{ml}$ of PEE $(5 \%, \mathrm{w} / \mathrm{v})$ was added to the mixture followed by continuous stirring on a magnetic stirrer $(150 \mathrm{rpm})$ for $20 \mathrm{~min}$. The last step was done by casting an amount of $100 \mathrm{ml}$ of the earlier mixture on petri dishes $(9 \mathrm{~cm} \times 9 \mathrm{~cm})$ and drying at oven at $65^{\circ} \mathrm{C}$ to obtain films of identical thickness. The dried films were finally skinned from the casting glass surface (figure, 1).

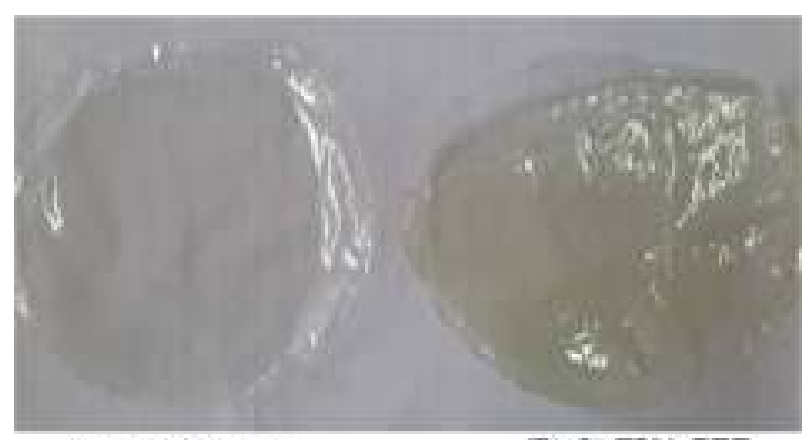

(A) $C_{s}$ PVA film

(B) CsTPVA-PEE

Fig.1. Edible film incorporated with pea peels ethanoic extract. Total phenolics and antioxidant activity of PPE incorporated films

A 0.2 gram of each film was placed in conical flasks holding $10 \mathrm{ml}$ of distilled water. The flasks were then kept at three different temperatures $\left(37,25\right.$ and $\left.4^{\circ} \mathrm{C}\right)$.

Aliquots of the supernatant were drawn at different time intervals $(30-720 \mathrm{~min})$ and examined for total polyphenol content and DPPH radical scavenging potential by the previously mentioned corresponding methods.

\section{Statistical Analysis}

All the trials were done in triplicate and the values assessed were displayed as mean \pm standard deviation through one-way analysis of variance (ANOVA). The statistical analysis was performed using SAS software (version 9.1, SAS Institute, Cary, NC, USA). Differences with $\mathrm{p}<0.05$ were considered significant.

\section{RESULTS AND DISCUSSION}

\section{Chemical analysis of raw materials}

An approximate analysis of pea peels was evaluated in the present study on a dry weight basis. Pea waste was rich in carbohydrate $(53.51 \mathrm{~g} / 100$ g.) contributing significantly to the total energetic value while low amount of fat $(4.00 \mathrm{~g} / 100 \mathrm{~g})$ was observed. Pea waste contained moderate amount of crude fiber (17.5\%). Moisture, protein and ash were existed in percentages of $9.00 \%, 11.49 \%$ and $4.50 \%$, respectively. Based on the results obtained, the chemical composition of pea waste agreed with that obtained by Rehman et al.( 2015) . On contrary, the study of Garg (2015) has reported lower crude fiber value $(7.86 \%)$. The contradictory results could be probably due to different genotypes and/or environmental conditions.

Determination of polyphenol and flavonoid contents

As shown in table (1), the successive fractions prepared by ethyl acetate and methylene chloride presented the maximum quantity of total polyphenols contents(TPC) i.e.; 165.43 and $156.33 \mathrm{mg}$ GAE /g extract, respectively. Ethanol extract revealed moderate quantity of total polyphenol content i.e. $112.46 \mathrm{mg}$ GAE /g extract. The total polyphenol content of solvent preparations obtained through butanol and aqueous residue were 106.46 and $87.23 \mathrm{mg}$ GAE /g extract, respectively . These results explain how the solvent polarity affects the distribution of phenolic compounds based on 'like dissolve like rule '. This shows that phenolic ingredients in pea peels crude ethanolic extract favor to be extracted with organic solvent having moderate polarity degree (semi-polar) such as methylene chloride and ethyl acetate than higher polarity solvents i.e. n-butanol and water. The maximum total phenolic content in ethyl acetate fraction shows that the main phenolic constituents in pea peels are semi polar compounds like free flavonoids. Overall, total polyphenolic contents in this study were greater than those obtained in earlier reports (Hadrich et al., 2014 ; Babbar et al., 2014) for different solvent extracts of pea peels.

Total flavonoids content (TFC) noticed in mother ethanol extract and fractions equivalent to quercetin (QE) were between 11.23and $26.63 \mathrm{mg} \mathrm{QE} / \mathrm{g}$ extract (table,1).

The flavonoid contents in ethyl acetate $(26.63 \mathrm{mg}$ $\mathrm{QE} / \mathrm{g}$ extract) and methylene chloride $(21.83 \mathrm{mg} \mathrm{QE} / \mathrm{g}$ extract) were higher when compared to the remaining fractions. This observation showed that greater flavonoid content is accompanied with higher total phenolic content.

Table1. Extraction yields, total polyphenolic content (TPC), total flavonoid content (TFC) and antioxidant activities of the extracts isolated from solvent fractionation of pea by-product.

\begin{tabular}{|c|c|c|c|c|c|c|}
\hline \multirow{2}{*}{$\begin{array}{l}\text { Extracts/ } \\
\text { reference } \\
\text { antioxidant }\end{array}$} & \multirow[b]{2}{*}{$\begin{array}{c}\text { Yield } \\
\%\end{array}$} & \multirow{2}{*}{$\begin{array}{c}\text { TPC } \\
\text { (mg GAE /g } \\
\text { extract }\end{array}$} & \multirow{2}{*}{$\begin{array}{c}\text { TFC } \\
\text { (mg quercetin } \\
\text { equivalent/g extract) }\end{array}$} & \multicolumn{3}{|c|}{ Total antioxidant capacity $\left(\mathrm{IC}_{50}\right)$} \\
\hline & & & & $\begin{array}{l}\text { DPPH } \\
(\mu \mathrm{g} / \mathrm{ml})\end{array}$ & $\begin{array}{c}\text { NO } \\
(\mu \mathrm{g} / \mathrm{ml})\end{array}$ & $\begin{array}{c}\mathrm{H}_{2} \mathbf{O}_{2} \\
(\mu \mathrm{g} / \mathrm{ml})\end{array}$ \\
\hline Et-OH & 18.55 & $112.46^{(\mathrm{c})} \pm 0.602$ & $16.53^{(\mathrm{d})} \pm 0.251$ & $340.90^{(b)} \pm 1.67$ & $511.30^{(\mathrm{b})} \pm 2.40$ & $384.60^{(\mathrm{c})} \pm 2.38$ \\
\hline $\mathrm{MC}$ & 6.58 & $156.33^{(\mathrm{b})} \pm 0.251$ & $21.83^{(\mathrm{b})} \pm 0.115$ & $271.36^{(\mathrm{c})} \pm 0.85$ & $377.30^{(\mathrm{d})} \pm 0.95$ & $354.83^{(\mathrm{d})} \pm 0.56$ \\
\hline Et.oAc & 2.45 & $165.43^{(\mathrm{a})} \pm 0.253$ & $26.63^{(a)} \pm 0.152$ & $167.23^{(\mathrm{e})} \pm 0.51$ & $302.36 \pm^{(\mathrm{e})} 1.10$ & $317.66^{(\mathrm{e})} \pm 1.53$ \\
\hline $\mathrm{Bu}-\mathrm{OH}$ & 21.40 & $106.46^{(\mathrm{d})} \pm 0.251$ & $17.30^{(\mathrm{c})} \pm 0.200$ & $260.66^{(\mathrm{d})} \pm 1.72$ & $412.76^{(\mathrm{c})} \pm 0.47$ & $455.03^{(b)} \pm 1.41$ \\
\hline WR & 31.76 & $87.23^{(\mathrm{e})} \pm 0.450$ & $11.23^{(\mathrm{e})} \pm 0.251$ & $680.40^{(\mathrm{a})} \pm 2.16$ & $1015.63^{(a)} \pm 1.66$ & $811.20^{(\mathrm{a})} \pm 1.35$ \\
\hline BHT & & & & $32.20^{(\mathrm{f})} \pm 1.95$ & $45.40^{(\mathrm{f})} \pm 0.36$ & $100.96^{(\mathrm{f})} \pm 2.60$ \\
\hline
\end{tabular}

Each value in the table is represented as Mean \pm SD $(n=3)$. Means not sharing the same letter are significantly different (LSD) at $p<0.05$ probability level in each column.

\section{HPLC analysis}

Forty one phenolic compounds of pea peels ethanolic extract could be detected and quantified using
HPLC technique (Table 2). The phenolic profile involved sixteen phenolic acids, twelve flavonoid glycosides and nine flavonoid aglycones with different concentrations. 
An Agilent 1100 Series HPLC equipped with diode array detector was conditioned to quantify free and bound flavonoids by using external standards. The major identified flavonoids with considerable amounts in pea peels ethanolic extract were hesperidin, luteo.6-arabinose8-glucose, and catechin with concentrations of 2017.2, 1692.9 and $1616.4 \mu \mathrm{g} / \mathrm{g}$ dry extract, respectively. Eleven flavonoids were detected in lower amounts as follows: luteo.6-glucose-8-arabinose (387.5 $\mu \mathrm{g} / \mathrm{g}$ ); naringin (359.3 $\mu \mathrm{g} / \mathrm{g})$; quercetin-3-O-glucoside (314.8 $\mu \mathrm{g} / \mathrm{g})$; apig.6rhamnose-8-glucose (222.1 $\mu \mathrm{g} / \mathrm{g}) \quad$; apig.6-glucose-8rhamnose $(194.0 \mu \mathrm{g} / \mathrm{g})$; rutin $(149.2 \mu \mathrm{g} / \mathrm{g})$; Acacetin $(115.3$ $\mu \mathrm{g} / \mathrm{g}) \quad ; \quad$ quercetrin $(101.7 \mu \mathrm{g} / \mathrm{g}) \quad ; \quad$ Kaemp.3-(2-pcomaroyl)glucose $(96.1 \mu \mathrm{g} / \mathrm{g}) \quad$;epicatechin $\quad(50.8 \mu \mathrm{g} / \mathrm{g}) \quad$; apig.7-O neohesperidoside $(44.3 \mu \mathrm{g} / \mathrm{g})$. Hesperetin, naringenin, a-pig.7-glucose, quercetin, apigenin, rhamnetin and kaempferol were also detected in trace amounts.

Phenolic acids and other phenols were identified and quantified using reversed phase HPLC (RPHPLC)/diode array detection (DAD). Pyrogallol was identified as the most abundant phenolic compound in pea waste ethanolic extract with noticeably high amount $(1511.7 \mu \mathrm{g} / \mathrm{g})$. Twelve phenolic acids were identified in lower amounts as follows: benzoic acid $(698.8 \mu \mathrm{g} / \mathrm{g})$; ellagic acid $(469.1 \mu \mathrm{g} / \mathrm{g})$; chlorogenic acid $(301.0 \mu \mathrm{g} / \mathrm{g})$; ferulic acid ( $217.8 \mu \mathrm{g} / \mathrm{g})$; protocatchuic acid $(201.6 \mu \mathrm{g} / \mathrm{g})$; p-OH benzoic acid $(160.1 \mu \mathrm{g} / \mathrm{g})$; gallic acid $(114.3 \mu \mathrm{g} / \mathrm{g})$; vanillic acid $(106.0 \mu \mathrm{g} / \mathrm{g})$; isoferulic acid $(59.9 \mu \mathrm{g} / \mathrm{g}) ; 3,4,5$ trimethoxycinnamic acid $(50.4 \mu \mathrm{g} / \mathrm{g})$; caffeic acid $(45.4$ $\mu \mathrm{g} / \mathrm{g})$; p-coumaric acid $(41.1 \mu \mathrm{g} / \mathrm{g})$. 4-amino benzoic, salicylic, cinnamic and rosmarinic acids were also detected in trace amounts.

As the literature data on the biochemical constituents of pea by-product crude extracts i.e metanolic or ethanolic extracts have restricted and only a few investigations have been undertaken up to now. The obtained results belonging the quantification of phenolic ingredients were too difficult to compare with literature. On the other hand, Seida et al. (2015) identified five quercetin derived glycosides from pea peels butanolic fraction using a validated HPLC method chromatographic fractionation. Recently, El-Feky et al. (2018) identified 35 phenolic compounds from pea peels ethyl acetate extract. Interestingly, they also identified hesperidin and pyrogallol as the largest polyphenolic compounds with amounts of 6059.54 and $860.06 \mu \mathrm{g} / \mathrm{g}$, respectively.

Table 2. Contents of flavonoids and phenolic compounds identified from pea peels $80 \%$ ethanolic extract.

\begin{tabular}{lccc}
\hline Compound & $\boldsymbol{\mu g} / \mathbf{g}^{*}$ & Compound & $\boldsymbol{\mu g} / \mathbf{g}^{*}$ \\
\hline Pyrogallol & 1511.7 & Cinnamic acid & 9.2 \\
Gallic acid & 114.3 & Kaempferol & 3.1 \\
4-amino benzoic acid & 31.7 & Rhamnetin & 10.5 \\
Protocatchuic acid & 201.6 & Apigenin & 14.4 \\
Catechin & 1616.4 & Luteo.6-arabinose-8-glucose & 1692.9 \\
Catechol & 62.1 & Luteo.6-glucose-8-arabinose & 387.5 \\
Chlorogenic acid & 301.0 & apig.6-rhamnose-8-glucose & 222.1 \\
Epicatechin & 50.8 & apig.6-glucose-8-rhamnose & 194.0 \\
p-OH benzoic acid & 160.1 & Naringin & 359.3 \\
Caffeine & 157.3 & Hesperidin & 2017.2 \\
Caffeic acid & 45.4 & Rutin & 149.2 \\
Vanillic acid & 106.0 & Quercetin-3-O-glucoside & 314.8 \\
P-coumaric acid & 41.1 & Rosmarinic acid & 5.1 \\
Ferulic acid & 217.8 & Apig.7-O-neohesperidoside & 44.3 \\
Isoferulic acid & 59.9 & Apig.7-glucose & 18.8 \\
Acacetin & 115.3 & Quercetrin & 101.7 \\
Ellagic acid & 469.1 & Quercetin & 17.8 \\
Benzoic acid & 698.8 & Kaemp.3-(2-p-comaroyl)glucose & 96.1 \\
3,4,5 trimethoxycinnamic acid & 50.4 & Naringenin & 22.1 \\
Coumarin & 120.5 & Hesperetin & 27.0 \\
Salicylic acid & 27.6 & &
\end{tabular}

\section{Anti- $\alpha$-amylase activity}

The development in the searching for effective low cost natural preparations for treatment of diabetes mellitus in developing countries has increased. However, nutritionists have recommended a healthy food intake along with daily exercise as an active way of controlling T2DM Wickramaratne et al. (2016). So supporting these populations for acceptable living style with the consumption of low cost natural preparations that have anti-diabetic potency in their daily diet would be one of the operative means of regulating blood glucose level. In this respect, the inhibitory action of pea peels ethanolic extract and its successive fractions $(3 \mathrm{mg} / \mathrm{ml})$ on the hydrolysis of starch in the presences of $\alpha$-amylase was monitored in nonpre-incubation and pre-incubation techniques. The lower amount of maltose formed in reaction tube returns to the higher of the anti- $\alpha$-amylase activity. The outcome of these trails is to identify low-cost strong $\alpha$-amylase inhibitors to alleviate $\mathrm{T}_{2} \mathrm{DM}$.

In non-pre-incubation technique, no pre-incubation was done between the enzyme and the tested extracts. Released maltose concentrations displayed by the extract ( $3 \mathrm{mg} / \mathrm{ml}$ ) using non- pre incubation are shown in table (3A). Butanol fraction showed higher $\alpha$-amylase inhibitory activity since less starch was hydrolyzed to maltose $(344.73 \mu \mathrm{g} / \mathrm{ml})$ after three minutes. The percentages of inhibition obtained in non pre incubation assay of pea peels extracts after 3 min were in the following order: butanol $32.87>$ ethyl acetate $16.42>$ ethanol $12.65>$ methylene chloride $11.26>$ water residue -1.21 . 
Table 3. Released maltose and percentages of inhibition of $\alpha$-amylase activity of examined samples using non-pre incubation and pre-incubation methods.

\begin{tabular}{|c|c|c|c|c|c|}
\hline \multirow{2}{*}{ Treatments } & \multicolumn{4}{|c|}{ (A) Maltose release $\mu \mathrm{g} / \mathrm{ml}$ ( non-pre- incubation method) } & \multirow[b]{2}{*}{$\% \mathbf{I}$} \\
\hline & Omin & $1 \mathrm{~min}$ & $2 \mathrm{~min}$ & 3min & \\
\hline$\overline{\mathrm{C}}$ & $34.20 \pm 2.56$ & $141.63^{(\mathrm{a})} \pm 2.91$ & $304.23^{(\mathrm{a})} \pm 3.68$ & $513.63^{(\mathrm{a})} \pm 4.15$ & \\
\hline $\mathrm{E}$ & $35.16 \pm 4.04$ & $134.03^{(\mathrm{b})} \pm 4.66$ & $284.73^{(\mathrm{bc})} \pm 3.57$ & $448.60^{(\mathrm{b})} \pm 3.55$ & $12.65^{(\mathrm{d})} \pm 1.18$ \\
\hline $\mathrm{MC}$ & $32.90 \pm 3.23$ & $130.60^{(b c)} \pm 2.90$ & $284.43^{(\mathrm{bc})} \pm 3.92$ & $455.73^{(\mathrm{b})} \pm 4.21$ & $11.26^{(\mathrm{d})} \pm 1.39$ \\
\hline Et.OAc & $36.16 \pm 2.88$ & $127.33^{(\mathrm{c})} \pm 3.32$ & $278.26^{(\mathrm{c})} \pm 5.11$ & $429.20^{(\mathrm{c})} \pm 5.64$ & $16.42^{(\mathrm{c})} \pm 1.75$ \\
\hline $\mathrm{Bu}-\mathrm{OH}$ & $35.50 \pm 4.58$ & $118.76^{(\mathrm{d})} \pm 3.38$ & $252.40^{(\mathrm{d})} \pm 5.01$ & $344.73 \pm^{(\mathrm{d})} 4.35$ & $32.87^{(\mathrm{b})} \pm 1.39$ \\
\hline WR & $35.56 \pm 4.53$ & $141.93^{(\mathrm{a})} \pm 3.39$ & $288.00^{(\mathrm{b})} \pm 6.87$ & $518.46^{(\mathrm{a})} \pm 4.70$ & $-1.21^{(\mathrm{e})} \pm 1.33$ \\
\hline $\mathrm{ACRB}$ & $34.86 \pm 4.46$ & $110.56^{(\mathrm{e})} \pm 5.15$ & $221.93^{(\mathrm{e})} \pm 4.04$ & $272.96^{(\mathrm{e})} \pm 5.03$ & $46.85^{(\mathrm{a})} \pm 0.55$ \\
\hline \multirow{2}{*}{ Treatments } & \multicolumn{4}{|c|}{ (B) Maltose release $\mu \mathrm{g} / \mathrm{ml}$ ( pre- incubation method) } & \\
\hline & $0 \mathrm{~min}$ & $1 \mathrm{~min}$ & $2 \mathrm{~min}$ & $3 \mathrm{~min}$ & $\% \mathrm{I}$ \\
\hline$\overline{\mathrm{C}}$ & $27.56 \pm 2.66$ & $151.70^{(\mathrm{a})} \pm 4.52$ & $354.43^{(\mathrm{a})} \pm 4.57$ & $589.66^{(\mathrm{a})} \pm 5.37$ & \\
\hline $\mathrm{E}$ & $29.53 \pm 2.66$ & $122.73^{(\mathrm{b})} \pm 4.95$ & $274.96^{(\mathrm{c})} \pm 5.37$ & $399.96^{(\mathrm{c})} \pm 4.57$ & $32.16^{(\mathrm{e})} \pm 0.32$ \\
\hline $\mathrm{MC}$ & $25.53 \pm 1.00$ & $119.36^{(\mathrm{b})} \pm 3.31$ & $252.13^{(\mathrm{d})} \pm 5.10$ & $344.73^{(\mathrm{d})} \pm 4.35$ & $41.52^{(\mathrm{d})} \pm 1.26$ \\
\hline Et.OAc & $26.23 \pm 4.08$ & $88.33^{(\mathrm{c})} \pm 4.31$ & $155.10^{(\mathrm{e})} \pm 6.75$ & $257.10^{(\mathrm{e})} \pm 5.28$ & $56.40^{(\mathrm{c})} \pm 0.52$ \\
\hline $\mathrm{Bu}-\mathrm{OH}$ & $27.56 \pm 2.66$ & $44.76^{(\mathrm{d})} \pm 3.92$ & $54.10^{(\mathrm{f})} \pm 4.03$ & $63.36^{(\mathrm{f})} \pm 4.72$ & $89.24^{(\mathrm{b})} \pm 0.89$ \\
\hline WR & $29.53 \pm 2.66$ & $126.36^{(\mathrm{b})} \pm 3.59$ & $286.53^{(\mathrm{b})} \pm 5.01$ & $445.80^{(\mathrm{b})} \pm 5.80$ & $24.38^{(\mathrm{f})} \pm 1.65$ \\
\hline $\mathrm{ACRB}$ & $26.23 \pm 0.55$ & $28.16^{(\mathrm{e})} \pm 3.12$ & $27.86^{(\mathrm{g})} \pm 2.65$ & $31.76^{(\mathrm{g})} \pm 4.75$ & $94.60^{(\mathrm{a})} \pm 0.83$ \\
\hline
\end{tabular}

(C) Maltose release $\mu \mathrm{g} / \mathrm{ml}$ of different conc of butanol fraction ( pre- incubation method)

\begin{tabular}{lccc}
\hline Conc. Of Bu-OH mg/ml & 0 min & $3 \min$ & \\
\cline { 1 - 3 } 0.5 & $27.56^{(\mathrm{ab})} \pm 2.66$ & $504.33^{(\mathrm{a})} \pm 5.30$ & \\
1.0 & $29.53^{(\mathrm{a})} \pm 2.66$ & $439.73^{(\mathrm{b})} \pm 5.58$ & $12.80^{(\mathrm{e})} \pm 0.87$ \\
1.5 & $25.53^{(\mathrm{ab})} \pm 1.00$ & $378.43^{(\mathrm{c})} \pm 4.61$ & $24.95^{(\mathrm{d})} \pm 1.01$ \\
2.0 & $26.20^{(\mathrm{ab})} \pm 4.13$ & $256.83^{(\mathrm{d})} \pm 5.71$ & $49.06^{(\mathrm{c})} \pm 1.44$ \\
2.5 & $24.16^{(\mathrm{b})} \pm 1.62$ & $169.86^{(\mathrm{e})} \pm 6.71$ & $66.31^{(\mathrm{b})} \pm 1.48$ \\
\hline
\end{tabular}

$\mathrm{C}=$ control $; \mathrm{E}=$ ethanol extract $; \mathrm{MC}=$ methylene chloride fraction $; \mathbf{E t . O A c}=$ ethyl acetate fraction $; \mathrm{Bu}-\mathrm{OH}=\mathrm{butanol}$ fraction $; \mathrm{WR}=\mathbf{w a t e r}$ residue ; $\mathrm{ACRB}=$ acarbose, $\mathrm{I} \%=$ percentage of inhibition.

Since pea peel extracts at a concentration of $(3 \mathrm{mg} / \mathrm{ml})$ showed inhibition percentages lower than $50 \%$ in non-pre incubation method, another experiment was conducted for the same extracts using pre-incubation method to evaluate if the $\alpha$-amylase inhibitory activities will be increased. Table $3 \mathrm{~B}$ shows that $\mathrm{Bu}-\mathrm{OH}$ and Et.OAc fractions which were previously pre-incubated with $\alpha$ amylase, recorded the lowest release of maltose at the end of the reaction period $(3 \mathrm{~min})$ with values of 63.36 and $257.1 \mu \mathrm{g} / \mathrm{ml}$, respectively. On other words, Bu-OH fraction showed the highest inhibitory ability against the enzyme with $89.24 \%$ inhibition at $3 \mathrm{mg} / \mathrm{ml}$ whereas, ethyl acetate fraction recorded considerable inhibitory action of $\alpha$ amylase (56.4\%).

Although pre-incubation protocol principally increases the inhibitory effect against $\alpha$-amylase for all examined samples, the inhibitory percentages still less than $50 \%$ for water residue, mother ethanol and methylene chloride solvent preparations i.e. the previously mentioned extracts are not so effective as $\alpha$-amylase inhibitors.

As $\mathrm{Bu}-\mathrm{OH}$ fraction possessed the most inhibitory activity, it was selected for estimation of $\mathrm{IC}_{50}$. Table (3C) showed a dose dependent effect of pea peels butanol fraction on starch break down as its concentration was inversely correlated with the formed maltose. The extract donated an $\mathrm{IC}_{50}$ value of $1.61 \mathrm{mg} / \mathrm{ml}$.

Conflicting results have documented in the literature regarding the inhibitory effect of ethyl acetate extract derived from pea peel on $\alpha$-amylase activity using pre-incubation route. Indeed, Hadrich et al. (2014) noted that pea peel derived ethyl acetate extract at a considerably low concentration $(1 \mathrm{mg} / \mathrm{ml})$ had high inhibitory activity against $\alpha$-amylase $(90.00 \%)$. While ethyl acetate fraction in this study recorded lower inhibitory activity $(56.40 \%)$ at higher concentration $(3 \mathrm{mg} / \mathrm{ml})$. Differences in extraction design and /or the composition of the by-product phenolic profile which was widely varied worldwide due to genetic and/or environmental factors could explain the discrepancy with previously reported data. Overall, many solvent extracts recorded higher in vitro $I C_{50}$ values for the inhibitory action against $\alpha$-amylase than that attained in this study for $\mathrm{Bu}-\mathrm{OH}$ fraction (Malathi et al. 2010 ; Mohamed et al. 2012 ; Dastjerdi et al. 2015). Phenolic compounds and flavonoids that exist in plant extracts may be accountable for the inhibition of starch hydrolyzing enzymes. In this respect, (Kwon et al. 2006 ; Tadera et al. 2006 ; Apostolidis et al. 2007) proposed that polyphenolic constituents may be liable for aiding $\alpha$-amylase inhibition and hence have been trusty attitude in controlling of blood glucose level in type 2 diabetic patients. In the present study, Bu-OH fraction did not record the highest polyphenolic content. However, it offered the most appropriate fraction against activity of $\alpha$-amylase. The present finding is in accordance with that obtained by; Mccue et al. (2005) who, established that, high polyphenolic content does not always refer a high inhibitory action on $\alpha$-glycosidase. They illustrated that starch breakdown was inhibited due to the non-phenolic profile in the extract. Recently, non-starch polysaccharides from natural sources have concerned as promising inhibitors for different glycosidases. For instance, Kashef et al. (2008) found that soybean hulls extracted 
galactomannan was able to inhibit the activity of $\alpha$-amylase by increasing the viscosity of reaction media and therefore, reducing enzyme-substrate bending ability. Actually, polar glycosides favor to be partitioned in polar solvent such as n-butanol (Seida et al., 2015). So, it could be undertaken that $\alpha$-amylase activity which was most extremely inhibited by $\mathrm{Bu}-\mathrm{OH}$ fraction, in the present study, may be partially due to its non-polyphenolic compounds in particular their polysaccharides.

\section{Anti-oxidant activity}

Antioxidant activity of mother ethanol extract and fractions of pea peels in the present study was evaluated using $\mathrm{DPPH}, \mathrm{NO}$ and hydrogen peroxide assays. $\mathrm{IC}_{50}$ can be defined as the concentration of the extract necessary to inhibit $50 \%$ of a radical. The lower $\mathrm{IC}_{50}$ value, the higher is the antioxidant potential.

In DPPH assay, ethyl acetate fraction showed smaller $\mathrm{IC}_{50}$ value $(167.23 \mu \mathrm{g} / \mathrm{ml})$ when compared to all tested samples (table, 1). Ethanol extract exhibited relatively higher $\mathrm{IC}_{50}$ value $(340.90 \mu \mathrm{g} / \mathrm{ml})$ than those of ethyl acetate, n-butanol $(260.66 \mu \mathrm{g} / \mathrm{ml})$ and methylene chloride $(271.36 \mu \mathrm{g} / \mathrm{ml})$ fractions; however aqueous fraction showed comparatively the highest value of all tested extracts $(680.40 \mu \mathrm{g} / \mathrm{ml})$. Based on the results attained, the great antioxidant potential of pea peels extracts agreed with those reported by Hadrich et al. (2014) using DPPH assay. Interestingly, the $\mathrm{IC}_{50}$ values of ethanol extract, ethyl acetate, methylene chloride and butanol fractions(table,1) in this study were lower than that previously reported for ethyl acetate extract $(350 \mu \mathrm{g} / \mathrm{ml})$ Hadrich et al. (2014). Similar observations have been also recognized by $E l$-Feky et al. (2018), who indicated strong antioxidant activity of $\mathrm{Pea}$ peels ethyl acetate fraction using DPPH radical assay. Noticeably, they recorded a moderate scavenging activity $(31.2 \%)$ of pea peels ethyl acetate fraction when examined at low concentration (50 $\mu \mathrm{g} / \mathrm{ml}$ ).

In NO assay, the scavenging activity of ethyl acetate fraction was higher $\left(\mathrm{IC}_{50}: 302.36 \mu \mathrm{g} / \mathrm{mL}\right.$, table 1) than those of other fractions. Overall, ascending $\mathrm{IC}_{50}$ values of pea peels solvent extracts using NO assay revealed the following order ethyl acetate $<$ methylene chloride $<$ butanol $<$ ethanol $<$ aqueous residual solution (table,1).

Table 1 shows that ethyl acetate fraction had also, the highest hydrogen peroxide scavenging activity $\left(\mathrm{IC}_{50}\right.$ : $317.66 \mu \mathrm{g} / \mathrm{ml}$ ) compared to other solvent preparations of pea by-product. The obtained $\mathrm{IC}_{50}$ values of ethanol extract, methylene chloride, butanol and water residue fractions using hydrogen peroxide assay were 384.60, $354.83,455.03$ and $811.20 \mu \mathrm{g} / \mathrm{ml}$, respectively. Overall, BHT as a reference antioxidant exposed the highest antioxidant capacity where it recorded the lowest $\mathrm{IC}_{50}$ values in the three antioxidant assays.

Correlation between the assessments of total antioxidant capacity with DPPH·, $\mathrm{NO}$ and $\mathrm{H}_{2} \mathrm{O}_{2}$ assays

To assess the appropriateness and reliability of the examined methods, used to evaluate the antioxidant capability of pea peels extracts, correlation study of the resultant values of antioxidant activity achieved by these methods was undertaken. Regression analysis using the Pearson correlation coefficients (R) and coefficients of determinations $\left(\mathrm{R}^{2}\right)$ is given in table (4) and figure (2). All $R$-values had positive significance level $(\mathrm{p}<0.05)$, demonstrating that the values of antioxidant activity determined by the examined procedures were extremely correlative. Also, it can be concluded that DPPH', NO and $\mathrm{H}_{2} \mathrm{O}_{2}$ assays were proper and dependable for estimating total antioxidant ability of pea peels extracts. Similar observations have been documented by Pande et al. (2017) , who stated some strong correlations $\left(R 0.920-0.955 \& R^{2}\right.$ $0.699-0.912$ ) between the assay methods used in estimating of total antioxidant activity of Bambusa tulda leaves extracts.

Table 4. Correlation $R$ and $\mathbf{R}^{2}$ between different antioxidant activity estimated by DPPH, NO and $\mathrm{H}_{2} \mathrm{O}_{2}$ assays and those between antioxidant assays and TP and TF of pea peel extracts.

\begin{tabular}{lcccc}
\hline Assays & DPPH & NO & $\mathbf{H}_{2} \mathbf{O}_{2}$ & TP \\
\hline $\mathrm{NO}$ & $0.995^{* *}(0.993)$ & & & \\
$\mathrm{H}_{2} \mathrm{O}_{2}$ & $0.957^{*}(0.942)$ & $0.969^{* *}(0.961)$ & & \\
$\mathrm{TP}$ & $-0.77(0.593)$ & $-0.779(0.606)$ & $0.789(0.622)$ & \\
$\mathrm{TF}$ & $-0.873^{*}(0.762)$ & $-0.861(0.741)$ & $-0.84(0.706)$ & $0.962 * *$ \\
\hline
\end{tabular}

$\mathbf{R}$, correlation coefficient. $\mathbf{R}^{2}$, coefficient of determinations. the values in parenthesis represent the $R^{2}$ values.

* significant level at $\mathbf{p}<0.05, * *$ significant level at $\mathbf{p}<0.01$

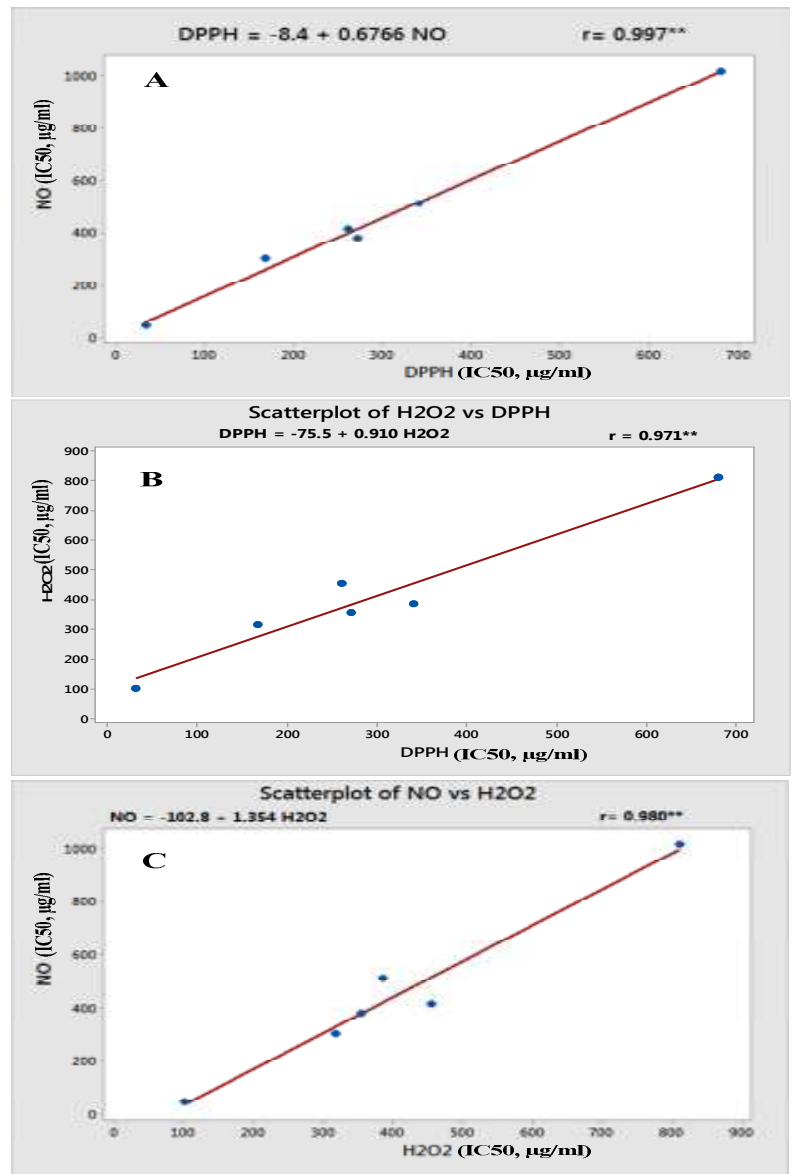

Fig 2 . Relationship between the antioxidant assays: (A) DPPH assay vs NO (B) $\mathrm{H}_{2} \mathrm{O}_{2}$ assay vs DPPH (C) NO assay vs $\mathrm{H}_{2} \mathrm{O}_{2}$

Correlation between total antioxidant capacity, TPs and TFs

As the total antioxidant activity of solvent extracts from natural sources is mostly attributed to phenolic 
constituents (Taher et al. 2016 ; Taher et al. 2018), a correlation analysis of total phenolics and flavonoids estimated in pea peels extracts with their antioxidant activity was performed and the results are shown in table (4). The Pearson's correlation coefficient between total polyphenol content of pea peels extracts with $\mathrm{IC}_{50}$ values of $\mathrm{DPPH}(\mathrm{R}=-0.770, \mathrm{p}<0.127), \mathrm{NO}(\mathrm{R}=-0.779, \mathrm{p}<$ $0.121)$ and $\mathrm{H}_{2} \mathrm{O}_{2}(\mathrm{R}=-0.789, \mathrm{p}<0.291)$ assays presented insignificant correlation. It means that total polyphenol content of pea peels extracts have no direct correlation with $\mathrm{IC}_{50}$ of total antioxidant capacity assays. This finding leads to the suggestion that while organic solvents were able to extract considerable amounts of phenolic constituents, not all ingredients correlated well with the obtained antioxidant capacity. It could be elucidated that each phenolic ingredient will reveal particular capacity or selectivity to react with specific target (Islam et al., 2016). The non-correlation between antioxidant action and total polyphenolic quantity in the present study is possibly due to the existence of other phytochemicals with antioxidant property (Ying et al. , 2013) .Overall the obtained results in this study are in agreement with the investigation of Ying et al. (2013) who stated that the quantity of total phenolic content did not reflex in their antioxidant capability using germinated and nongerminated legume extracts.

Total flavonoid content in pea peels extracts had a significant and negative correlation with $\mathrm{IC}_{50}$ of DPPH (R $=-0.873, \mathrm{p}<0.049$, fig 3 ). Increasing in total flavonoid content will provide greater antioxidant capacity i.e. lower $\mathrm{IC}_{50}$ value. It may be thought that flavonoids in pea peels extracts were the major conistituents responsible for the obtained antioxidant capacity by DPPH method. Moreover, hesperidin; the most principal phenolic compound identified in this study; has been described to possess antioxidant activity (Wilmsen et al., 2005). Overall, the distribution of hesperidin and other flavonoids between solvent fractions and the selective activity of each flavonoid as antioxidant may be accountable for the obtained antioxidant capacity of each fraction using DPPH assay.

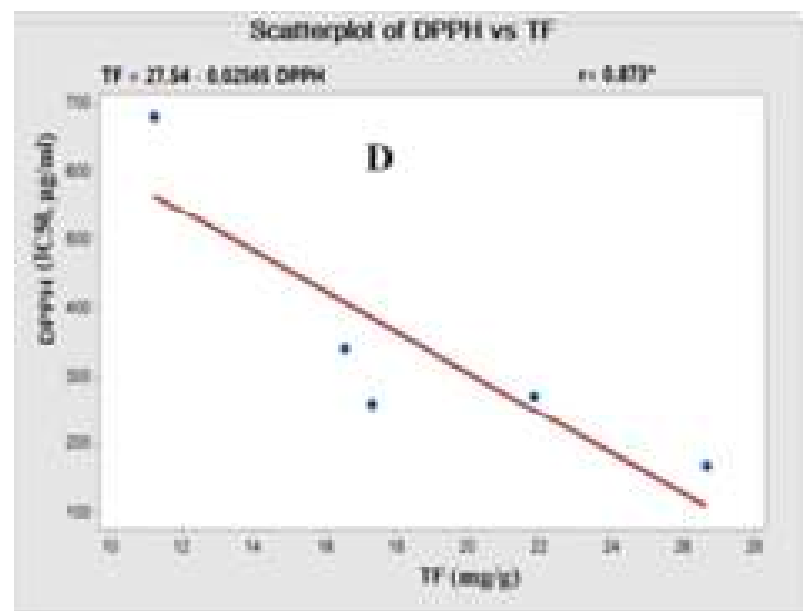

Fig 3. Relationship between the total antioxidant activities and TF using DPPH scavenging assay
Evaluation of Cs/PVA/PEE film as antioxidant donor

To enhance the usage of polymer films in food technology, the incorporation of these films with plant extracts rich in antioxidant has been reported to improve food safety and quality assurance Kanatt et al (2012). Blending synthetic polymer PVA with chitosan enhances the physical and mechanical properties of chitosan. Moreover incorporation of Cs/PVA with different plant extracts has been reported to be an effective tool in food packaging without any undesirable properties Kanatt et al (2012). Based on prior data, the present part will merely evaluate release of phenolics and antioxidant from Cs/PVA film incorporated with pea peels ethanolic extract under different temperatures as those used during food storage i.e. 4,25 and $37^{\circ} \mathrm{C}$. The higher release of phenolics from the biofilm indicates higher release of natural antioxidant responsible for combating the deterioration in food quality.

When Cs/PVA/PEE film dipped in distilled water, it hydrated, swelled and sequentially lost its structural firmness and released the active antioxidants (Flores et al.,2007) . In the present study, PEE supplemented the polymer composite film with a considerable amount of phenolic compounds. Moreover, the release of these phenolics from Cs/PVA film was directly affected by the temperature (table, 5). As shown in table 5, a minimum release of phenolics from the biodegradable film was obtained at low temperature (4 C), where its values were $88.86,147.33$ and $291.66 \mu \mathrm{g} / \mathrm{g}$ after dipping in distilled water for 30,120 and $720 \mathrm{~min}$ respectively. While significantly high phenolics were released from films stored at $37 \mathrm{C}$, where their values were $217.53,401.10$ and $811.30 \mu \mathrm{g} / \mathrm{g}$ after dipping in distilled water for 30,120 and $720 \mathrm{~min}$, respectively. The obtained results agreed in a large extend with those obtained by Kanatt et al. (2012) who stated that the release of the phenolic compounds from films incorporated with mint and pomegranate extracts was temperature dependent and the maximum release achieved at high temperature.

Incorporation of plant extracts rich in phenolics in edible films donated antioxidant ability to these films, since a significant amount of the phenolics in the films exist in soluble form. Moreover, total polyphenolic content of the film largely associated with the antioxidant ability estimated by DPPH assay.

Table 5 also displays the DPPH radical scavenging ability of the Cs/PVA film enriched with PPE. Control Cs/PVA film (not containing PEE) did not display any anti-radical activity for DPPH (data not shown). Once Cs/PVA film incorporated with PEE, the polymer film exhibited anti-radical activity as shown in (table 5). The release of natural products from edible films is mainly depending on handling temperature. At lower temperature (4C), PEE phenolic compounds was released less from the bi-polymer films while at higher temperatures $\left(37^{\circ} \mathrm{C}\right)$ the anti-radical action of Cs/PVA film was significantly increased due to fast release of phenolics from the film. Cs/PVA film recorded the best percentages of scavenging DPPH as 34.46, 55.43 and 85.56 after incubation with distilled water at $37 \mathrm{C}$ for 30,120 and $720 \mathrm{~min}$, respectively. 
Taher, M. A.

Table 5. Released phenolics(TP) and DPPH scavenging activity (I\%) of Cs/PVA film incorporated by PEE.

\begin{tabular}{lcccccc}
\multirow{2}{*}{$\begin{array}{l}\text { Time } \\
\text { min) }\end{array}$} & \multicolumn{2}{c}{$\mathbf{4}^{\circ} \mathbf{C}$} & \multicolumn{2}{c}{$\mathbf{2 5}^{\circ} \mathbf{C}$} & \multicolumn{2}{c}{$\mathbf{3 7} \mathbf{C}$} \\
\cline { 2 - 7 } & $\mathbf{T P}(\boldsymbol{\mu g} / \mathbf{m l})$ & $\mathbf{\%} \mathbf{I}$ & $\mathbf{T P}(\boldsymbol{\mu \mathbf { g }} / \mathbf{m l})$ & $\mathbf{\%} \mathbf{I}$ & $\mathbf{T P}(\boldsymbol{\mu \mathbf { g }} / \mathbf{m l})$ & $\mathbf{\%} \mathbf{I}$ \\
60 & $88.86^{(\mathrm{c})} \pm 3.09$ & $5.56^{(\mathrm{c})} \pm 0.11$ & $135.86^{(\mathrm{b})} \pm 1.87$ & $10.36^{(\mathrm{b})} \pm 0.61$ & $217.53^{(\mathrm{a})} \pm 2.60$ & $34.46^{(\mathrm{a})} \pm 0.98$ \\
60 & $121.06^{(\mathrm{c})} \pm 3.20$ & $8.10^{(\mathrm{c})} \pm 0.80$ & $191.43^{(\mathrm{b})} \pm 2.50$ & $15.60^{(\mathrm{b})} \pm 0.60$ & $235.33 \pm^{(\mathrm{a})} 2.25$ & $36.46^{(\mathrm{a})} \pm 0.96$ \\
120 & $147.33^{(\mathrm{c})} \pm 2.75$ & $17.46^{(\mathrm{c})} \pm 0.57$ & $237.83^{(\mathrm{b})} \pm 2.25$ & $21.46^{(\mathrm{b})} \pm 1.2$ & $401.10^{(\mathrm{a})} \pm 3.15$ & $55.43^{(\mathrm{a})} \pm 1.25$ \\
360 & $189.00^{(\mathrm{c})} \pm 2.30$ & $30.30^{(\mathrm{c})} \pm 1.27$ & $406.03^{(\mathrm{b})} \pm 2.05$ & $42.56^{(\mathrm{b})} \pm 2.05$ & $711.76^{(\mathrm{a})} \pm 3.65$ & $77.26^{(\mathrm{a})} \pm 1.33$ \\
720 & $291.66^{(\mathrm{c})} \pm 3.91$ & $40.70^{(\mathrm{c})} \pm 1.65$ & $531.63^{(\mathrm{b})} \pm 5.38$ & $55.63^{(\mathrm{b})} \pm 2.25$ & $811.30^{(\mathrm{a})} \pm 4.00$ & $85.56^{(\mathrm{a})} \pm 1.60$ \\
\hline
\end{tabular}

The previous results agreed with those obtained by Mayachiew and Devahastin(2010) who stated that bioactive constituents were rapidly released from Cs films enriched with Indian gooseberry during the first period $(8$ h) and then was rather constant in the second phase (8-24 h).On contrary, our results disagreed with those obtained by Kanatt et al. (2012) who found that phenolic compounds were released from Cs/PVA film enriched with natural extracts in the first $30 \mathrm{~min}$ and after this period, DPPH scavenging ability of these films did not considerably increase.

\section{CONCLUSION}

The opportunity of valorization of pea peels for developing anti- $\alpha$-amylase inhibitors and antioxidants was investigated. Obtained data showed that the components of pea peels butanolic fraction possess high anti- $\alpha$-amylase activity $\left(\mathrm{IC}_{50}=1.61 \mathrm{mg} / \mathrm{ml}\right)$. Therefore, it could be used in alleviating T2DM through suppress intestinal glucose absorption. This study shows also strong antioxidant activity of pea by-product ethyl acetate fraction with $\mathrm{IC}_{50}$ values of $167.23,302.36$ and $317.66 \mu \mathrm{g} / \mathrm{ml}$ when evaluated by $\mathrm{DPPH}, \mathrm{NO}$ and $\mathrm{H}_{2} \mathrm{O}_{2}$ assays, respectively. A significant and negative correlation was achieved between total flavonoids content and $\mathrm{IC}_{50}$ when evaluated by $\mathrm{DPPH}$ assay. An edible film consisted of Cs/PVA biopolymer enriched with pea peels ethanol extract was developed and monitored for the release of polyphenols and antioxidants under different temperatures. After 120 minutes of dipping $\mathrm{Cs} / \mathrm{PVA} / \mathrm{PEE}$ polymer in water at $(37 \mathrm{C})$, the anti-DPPH activity $(55.43 \%)$ of edible film was significantly increased in comparison with those maintained at lower temperatures due to the fast release of phenolics $(401.10 \mu \mathrm{g} / \mathrm{ml})$. So, it could be concluded that edible film enriched with pea byproduct extract improves nutritional and aesthetic quality features of food products.

\section{REFERENCES}

Abas , F.O. and Halim,A.M. (2017) . Design a mechanicalbiological system for treatment biological wastes (orange peels, Peel peas, Okra shell) with optimization and qualification for liberal and residue products. Advances in Environmental Biology, 11,2, 71-83.

Ali, H.; Houghton, P. J. and Soumyanath, A. (2006). $\alpha-$ Amylase inhibitory activity of some Malaysian plants used to treat diabetes; with particular reference to Phyllanthusamarus. J Ethnopharmacol. 107, 3, 449-455.

AOAC Association of Official Analytical Chemists. Official methods of analysis ( $17^{\text {th }}$ ed.). Washington DC.USA: The Association. (2000)
Apostolidis, E.; Kwon, Y. and Shetty, K. (2007). Inhibitory potential of herb, fruit and fungal-enriched cheese against key enzymes linked to type 2 diabetes and hypertension. Innovative Science Emerging Technology 8, 1, 46-54.

Babbar, N.; Oberoi, H.S.; Sandhu, S.K. and Bhargav, V.K. (2014). Influence of different solvents in extraction of phenolic compounds from vegetable residues and their evaluation as natural sources of antioxidants. J Food Sci Technol. 5, 10, 25682575.

Basu, S. (2016).Colour removal of textile industry effluent using waste pea pods as adsorbent. International Research Journal of Engineering and Technology (IRJET) ,3 , 12,190-192.

Dastjerdi, Z.M.; Namjoyan, F. and Azemi, M.E. (2015). Alpha Amylase Inhibition Activity of Some Plants Extract of Teucrium Species. European Journal of Biological Sciences, 7, 1, 26-31.

Dod, R.; Banerjee, G. and Saini, S. (2012). Adsorption of Methylene Blue Using Green Pea Peels (Pisum sativum): A Cost-effective Option for Dye-based Wastewater Treatment. Biotechnology and Bioprocess Engineering, 17,862-874.

El-Feky, A.M.; Elbatanony, M. M. and Mounier, M. M. (2018) .Anti-cancer potential of the lipoidal and flavonoidal compounds from Pisum sativum and Vicia faba peels. Egyptian Journal of Basic and Applied Sciences, 5, 4, 258-264.

Flores, S.; Conte, A.; Campos, C.; Gerschenson, L. and Nobile, M. D. (2007). Mass transport properties of tapioca-based active edible films. Journal of Food Engineering,81, 580-586.

Garg, M. (2015). Nutritional Evaluation and Utilization of Pea Pod Powder for Preparation of Jaggery Biscuit .J Food Process Technol 6, 522, doi:10.4172/21577110.1000522 Page

Goupy, P.; Hugues, M.; Boivin, P. and Amiot , M.J. (1999). Antioxidant composition and activity of barley (Hordeum vulgare) and malt extracts and isolated phenolic compounds. Journal of the Science of Food and Agriculture, 79, 1625-1634.

Green, L.C.; Wagner, D.A.; Glogowski, J.; Skipper, P.L.; Wishnok, J.S. and Tannenbaum, S.R.(1982). Analysis of nitrate, nitrite, and $[15 \mathrm{~N}]$ nitrate in biological fluids. Analytical Biochemistry, 126,1, 131-138.

Guilbert, S.; Contard, N. and Gorris, L.G.M. (1996). Prolongation of shelf-life of perishable food products using biodegradable films and coatings. Lebensmittel- Wissenschaft und-Technologie, 29, $10-17$. 


\section{J.Agric.Chem.and Biotechn., Mansoura Univ.Vol. 10(1), January, 2019}

Gupta, G.P. and Premavalli, K.S. (2011): In vitro studies on functional properties of selected natural dietary fibers. Int J Food Prop. 14,397-410.

Hadrich, F.; Arbi, M.E.; Boukhris, M.; Sayadi, S. and Cherif, S. (2014). Valorization of the peel of pea: Pisumsativum by evaluation of its antioxidant and antimicrobial activities.J Oleo Sci. 63, 11, 1177-83.

Islam, T.;Yu, X. and Xu, B. (2016). Phenolic Profiles, Antioxidant Capacities and Metal Chelating Ability of Edible Mushrooms Commonly Consumed in China. LWT - Food Science and Technology, 72,423-431.

Iwata ,E.; Hotta, H. and Goto ,M. (2009). The screening method of a bifidogenic dietary fiber extracted from inedible parts of vegetables. J Nutr Sci Vitamino. 55,385-388

Kanatt, S.R.; Chander, R.and Sharma, A. (2007). Antioxidant Potential of Mint (Menthaspicata L.) in Radiation-Processed Lamb Meat. Food Chemistry, 100, 451-458.

Kanatt, S. R.; Chander, R. and Sharma, A. (2010). Antioxidant and antimicrobial activity of pomegranate peel extract improves the shelf life of chicken products. International journal of food science and technology, 45, 2, 193-415.

Kanatt, S.R.; Rao, M.S.; Chawla, S.P. and Sharma A. (2012). Active chitosane polyvinyl alcohol films with natural extracts Food Hydrocolloids 29, 290 297.

Kashef, R.K.H.; Hassan, H.M.M.; Afify, A.S.; Ghabbour,S.I. and Saleh, N.T. (2008). Effect of Soybean Galactomannan on the Activities of $\alpha$ Amylase, Trypsin, Lipase and Starch Digestion. Journal of Applied Sciences Research, 4,12, 1893 1897.

Khattab, H.A. and Abdel Wahab, H.M. (2005) . Effect of inclusion pea or broad bean husks in diet of hypercholesterolemic rats. Sci Med J ,17, 17-33.

Kwon, Y.I.; Apostolidis, E. and Shetty, K. (2007). Evaluation of pepper (Capsicum annuum) for management of diabetes and hypertension. Journal of Food Biochemistry, 31, 370-385.

Kwon, Y.;Vattem, D. and Shetty, K. (2006). Clonal herbs of Laminaceae species against diabetes and hypertension. Asia Pacific Journal of Clinical Nutrition 15,1, 107-118.

Lin, J.Y. and Tang, C.Y. (2007). Determination of total phenolic and flavonoid contents in selected fruits and vegetables, as well as their stimulatory effects on mouse splenocyteproliferation. Food Chemistry, 101, 140-147.

Lo'ay ,A. A. and Taher, M. A. (2018). Influence of edible coatings chitosan/PVP blending with salicylic acid on biochemical fruit skin browning incidence and shelf life of guava fruits cv. 'Banati'. Scientia Horticulturae 235:424-436.

Malathi, V.; Devi, S. and Revanthi, K. (2010).Anti diabetic activity by the in vitro alpha amylase and alphaglucosidase inhibitory activity of Catharanthus roseus. Bioscan, 5, 4, 655-659.
Mary, S.G.; Sugumaran1, P.; Niveditha, S.; Ramalakshmi, B.; Ravichandran1, P. and Seshadr,S. (2016). Production, characterization and evaluation of biochar from pod (Pisumsativum), leaf (Brassica oleracea) and peel (Citrus sinensis) wastes. Int $\mathrm{J}$ Recycl Org Waste Agricult 5, 43-53.

Mattila, P.; Astola, J. and Kumpulainen, J. (2000). Determination of flavonoids in plant material by HPLC with diode-array and electro-array detections. Journal of the Science of Food and Agriculture, 48, 5834-5841.

Mayachiew, P.and Devahastin, S. (2010). Effects of drying methods and conditions on release characteristics of edible chitosan films enriched with Indian gooseberry extract. Food Chemistry, 118, 594-601.

Mccue, P.; Kwon, Y.I. and Shetty, K. (2005).Antiamylase, anti-glucosidase and anti-angiotensin Iconverting enzyme potential of selected foods. Journal of Food Biochemistry. 29, 3, 278-294.

Mohamed, E.A.H.; Siddiqui, M. J.A.; Ang, L. F.;Sadikun, A.; Chan, S.H.; Tan, S.C.; Asmawi, M. Z. and Yam, M. F. (2012). Potent $\alpha$-glucosidase and $\alpha$ amylase inhibitory activities of standardized $50 \%$ ethanolic extracts and sinensetin from Orthosiphonstamineus Benth as anti-diabetic mechanism. Complementary Medicine Research (ISCMR) 12,176.

Mualikrishna, G. and Tharanathan, R. N. (1994). Characterization of pectic polysaccharides from pulse husks. Food Chemistry ,50, 1, 87-89.

Nitin, K.S.; Vivek, K.T. and Santosh, K.M. (2017). The Production of Xylanase Enzyme (E.C. Number = 3.2.1.8) Using Solid Substrate Fermentation. Biotechnol Ind J. 13,4,145.

Oktay, M.;Gulcin, I. and Kufrevioglu, I. (2003). Determination of in vitro antioxidant activity of fennel (Foeniculum vulgare) seed extracts. Labenson-Wiss U-Technol 36, 263-271..

Pande, H.; Kumar,B. and Varshney V. K. (2017). Phenolic Composition and Antioxidant Capacity of Biomass Residue (Leaves) Generated from Bambusa tulda Plantations. Waste Biomass Valor. 8,2349-2362.

Pathak, P.D. ;Mandavgane, S. A. and Kulkarni ,B. D. (2017). Valorization of Pomegranate Peels: A Biorefinery Approach. Waste and Biomass Valorization, 8, 4, 1127-1137.

Rehman, A.; Gulfraz, M.; Kaukab, G.; Muhammed, R. H. and Anwar, Z . (2015). A Comprehensive Approach to Utilize an Agricultural Pea peel (Pisumsativum) Waste as a Potential Source for BioethanolProduction. Romanian Biotechnological Letters Vol. 20, 3, 10422-10430 .

Saltos, M.B.V.; Puente, B.F.N.; Faraone, I.; Milella, L.,; De Tommasi, N. and Braca, A. (2015). Inhibitors of $\alpha-$ amylase and $\alpha$-glucosidase from Andromachiaigniaria Humb.\& Bonpl. Phytochem. Lett.14, 45-50.

Seida, A.A.; Nebal, D.E.; Wafaa, T.I.; Hanaa, H.E.; El Maraghy, S. and Amira, S.E. (2015). Bioassayguided fractionation of a hepatoprotective and antioxidant extract of pea by-product Natural Product Research, 29, 16, 1578-1583. 
Taher, M. A.

Shirwakar, A.; Shirwakar, A.R.; Rajendran, K. and Punitha, I.R.S. (2006). In Vitro antioxidant studies on the benzyltetraisoquinoline alkaloid berberine. Biological and Pharmaceutical Bulletin, 29, 19061910.

Singleton, V.L.; Orthofer, R. and Lamuela-Raventos, R.M. (1999). Analysis of total phenols and other oxidation substrates and antioxidants by means of Folin-Ciocalte reagent. Methods in Enzymology, 299, 152-178.

Tadera, K.; Minami, Y.; Takamatsu, K. and Matsuoka, T. (2006). Inhibition of $\alpha$-glucosidase and $\alpha$-amylase by flavonoids. Journal of Nutritional Science and Vitaminology. 52, 149-153.

Taher, A. M. ; Dawood, H. D.; Sanad, I. M.and Hassan, A. R. (2016). Searching for antihyperglycemicphytomolecules of Tecomastans. European Journal of Chemistry, 7, 397-404.

Taher, M.A.; Tadros, L.K. and Dawood, D.H. (2018). Phytochemical constituents, antioxidant activity and safety evaluation of Kei-apple fruit (Dovyalis caffra). Food Chemistry 265, 144-151.
Verma, N.; Bansal, M. and Kumar, V. (2011). Pea peel waste: A lignocellulosic waste and its utility in cellulase production BY Trichodermareesei under solid state cultivation.bioresourses , 6, 2,15051519 .

Wickramaratne,M. N.; Punchihewa, J. C. and Wickramaratne ,D. B. M. ( 2016). In-vitro alpha amylase inhibitory activity of the leaf extracts of Adenanthera pavonina. BMC Complement Altern Med. 16, 466 doi:10.1186/s12906-016-1452-y

Wilmsen, P.K.; Spada, D.S. and Salvador, M. (2005). Antioxidant activity of the flavonoid hesperidin in chemical and biological systems.JAgric Food Chem. 53, 12, 4757-4761.

Ying, C.M.; Azlan, A.; Al-Sheraji, S. H.; Hassan, F. A. and Prasad, K. N.(2013). Antioxidant Activities and Total Phenolic Content in Germinated and NonGerminated Legume Extracts Following AlkalineAcid Hydrolysis. Pakistan Journal of Nutrition ,12 ,12, 1036-1041.

\section{من المخلف المى المنفعة :تقييم النشاطات المثبطة لانزيم الالفا اميليز والمضادة للاكسدة بالاضافة الى تطوير فيلم تظليف نشط نحو تثمين قشور البسلة محمد عبد الحميل طاهر قسم الكيمياء الزراعية ـ كلية الزراعة جامعة جلة المنصورة}

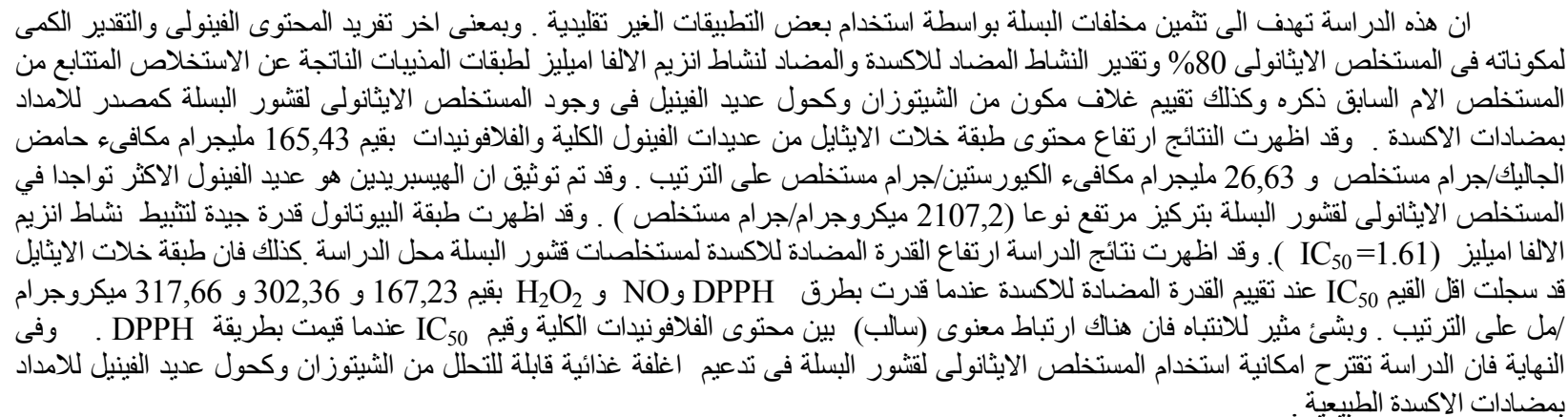

